\title{
Endogenous biotin expression in renal and testicular tumours and literature review
}

\author{
Nader Fahmy, MD, FRCSC, PhD; ${ }^{*}$ Mark Woo; ${ }^{*}$ Mona Alameldin, MD; ${ }^{+}$Joe King Lee, MD; Kyle MacDonald,

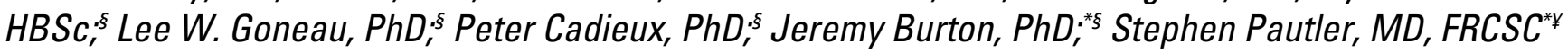

*Division of Urology, Department of Surgery, Western University, London ON; ' †epartment of Anatomical Pathology, Western University, London ON; §Department of Microbiology and Immunology, Western University, London ON; * Division of Surgical Oncology, Department of Oncology, Western University, London ON

Cite as: Can Urol Assoc J 2014;8(7-8):268-72. http://dx.doi.org/10.5489/cuaj.1810

Published online August 11, 2014.

\section{Abstract}

Introduction: The aim of this study was to examine endogenous biotin levels in tumour specimens collected from patients with renal and testicular tumours and compare them to the surrounding non-neoplastic surgical margin.

Methods: Frozen samples were obtained from the Ontario Tumour Bank. Renal and testicular tumour tissue were included in this study. Normal tissue from the negative surgical margins of each tumour served as a control. Biotin detection in tissue specimens was determined using immunohistochemistry (IHC).

Results: Specimens collected from 56 patients (36 men and 20 women) were included in this study. Histopathology of the 52 renal tumours included 31 (60\%) conventional type RCC, 5 (10\%) chromophobe RCC, 5 (10\%) papillary RCC, 1 (2\%) oncocytoma and $10(19 \%)$ upper tract urothelial carcinoma (UC). The 4 testicular tumours included 1 seminomatous (25\%) germ cell tumour and $3(75 \%)$ non seminomatous germ cell tumours.

Conclusion: No biotin signal was perceived in all tested tumour samples. Endogenous biotin expression was detected in the matching non-neoplastic surgical margin of tested renal tissues. This lack of staining may prove to be a valuable tool in future studies.

\section{Introduction}

Renal cancer is the 6th most common non-cutaneous cancer in males and the 11th in females. A total of 5900 new cases of renal cancers are estimated to be diagnosed in Canada in 2013. The province of Ontario has the largest estimated incidence of renal cancer. ${ }^{1}$ Advances in the understanding of the molecular pathology and biology of renal tumours are needed to enhance patient diagnosis and improve survival rates. Testis cancer is on the rise in Ontario.

Eight decades ago, studies demonstrated that abundant amounts of endogenous biotin is present in renal tissues. ${ }^{2}$
Biotin, also known as vitamin B7, vitamin $\mathrm{H}$ or coenzyme $\mathrm{R}$ plays a fundamental role in cell growth. It is an essential component in the metabolism of carbohydrates, lipids and proteins and is an important cofactor in the citric acid cycle. It is involved in gluconeogenesis, lipogenesis, synthesis of isoleucine and valine and in the catabolism of branched-chain amino acids. ${ }^{3}$ Low levels of biotin have been reported in alcoholics ${ }^{4}$ and epileptics. ${ }^{5}$ Biotin was also thought to possibly have procarcinogenic effects in experimental animals. ${ }^{6}$

The aim of this study was to determine endogenous biotin expression in renal, urothelial and testicular tumours and in their adjacent matching non neoplastic surgical margin.

\section{Methods}

This research was approved by our institutional Research Ethics Board.

\section{Materials}

Biological materials were provided by the Ontario Tumour Bank, which is funded by the Ontario Institute for Cancer Research (OICR). It is a province-wide biorepository and data bank focused on collecting tumour-related human biospecimens. Specimens include fresh-frozen tissue biopsies collected from patients with renal or testicular tumours. Each case in the OICR Tumour Bank has well-characterized clinical and pathological information. All frozen tissue biopsies included tumour specimens and matching controls collected from their corresponding non-neoplastic negative surgical margins. All samples were stored at $-80^{\circ} \mathrm{C}$.

\section{Tissue preparation}

Collected frozen tissues were cut into 4- $\mu \mathrm{m}$ sections using the Leica CM3050 S Cryostat (Leica Biosystems GmbH, Nussloch, Germany). Pairs of contiguous tissue sections 
were mounted on VWR Superfrost glass microslides (VWR international LCC, Radnor, PA) and stored at $-80^{\circ} \mathrm{C}$.

\section{Immunohistochemistry}

\section{Testing endogenous biotin expression in frozen tissues}

Immunohistochemistry (IHC) was performed on the frozen tumour and their matching non-neoplastic negative surgical margin to determine the presence and location of endogenous biotin. Following defrosting of the slides, the tissue was fixed for 10 seconds in cold acetone. Endogenous peroxidase activity was quenched with $3 \%$ hydrogen peroxide diluted in absolute methanol. Blocking of non-specific binding was performed by incubating the slides in $20 \%$ heat-inactivated normal horse serum (Vector Laboratories, Inc., Burlingame, CA). Slides were then incubated at room temperature for 1 hour in AffiniPure rabbit polyclonal antibiotin IgG antibody (Bethyl Laboratories Inc., Montgomery, TX) at a dilution of 1:200. A subsequent secondary incubation was done at room temperature for 30 minutes, using a goat anti-rabbit IgG polyclonal antibody conjugated with horseradish peroxidase (HRP) (Jackson ImmunoResearch Inc., West Grove, PA) at a dilution of 1:500. A 3, 3'-diaminobenzidine (DAB) Peroxidase Substrate Kit, (Vector Laboratories, Inc., Burlingame, CA) was used for visualization. Sections were counterstained with hematoxilyn and dehydrated using the Leica Autostainer XL Staining System ST5010 (Leica Biosystems GmbH, Nussloch, Germany). Slides were mounted in Surgipath Micromount mounting medium (Leica Biosystems Richmond Inc, Richmond, IL). Samples were examined by one pathologist using an Olympus BX51 optical microscope (Olympus America Inc, Center Valley, PA). Pictures were captured using high quality microscope SPOT Insight 2-Mb colour camera and analyzed using SPOT Basic Software version 4.1 (SPOT Imaging Solutions, MI). Tissue sections incubated without primary or secondary antibodies served as negative internal controls.

\section{Results}

In total, 56 frozen specimens, including 52 renal and 4 testicular tumour tissues, along with their corresponding non neoplastic negative surgical tissue margins were provided by the Ontario Tumour Bank for the purpose of this study. Specimens were collected from 36 men and 20 women with a mean age of 62.8 years (median: 68; range: $37-82$ ).

\section{Tumour characteristics}

The mean renal tumour size was $6.52 \mathrm{~cm}$ (median $5.5 \mathrm{~cm}$; range: $2.8-14$ ). Renal tissue samples were collected from patients who had undergone 5 laparoscopic radical nephrectomies, 37 open radical nephrectomies and 10 nephroureterectomies. Three patients died of their disease. Histopathology of the renal tumours included $31(60 \%)$ conventional type renal cell carcinoma (RCC), 5 (10\%) chromophobe, 5 (10\%) papillary, 1 (1\%) oncocytoma and 10 (19\%) upper tract urothelial cancer (UC) (Table 1).

The mean testicular tumour size was $3.15 \mathrm{~cm}$ (range: 2.5-4). Testicular tissue samples were collected from 4 patients who had undergone inguinal orchiectomies. One patient had a seminomatous germ cell tumour and 3 had non-seminomatous germ cell pathology (Table 1).

\section{Biotin localization in frozen tissue samples}

There was no biotin staining detected within all tested renal and testicular tumour tissue samples within all histologic subtypes. Robust intra-cytoplasmic biotin staining was only detected within the matching non-neoplastic negative surgical margin of malignant renal tumours. There was no biotin staining detected in non-neoplastic testicular tissue (Fig. 1).

\section{Discussion}

The absence of endogenous biotin staining in renal and testicular tumour tissues in this study was initially detected as an incidental finding while exploring other potential tumour markers by IHC. While investigating our preliminary results, we determined that the detected IHC staining was the result of a diagnostic pitfall produced by the cross reactivity of endogenous biotin with the avidin-biotin-peroxidase complex $(\mathrm{ABC})$ system used in common IHC protocols. ${ }^{7}$

IHC techniques exploit the principle of an antibody binding to a specific antigen. By taking advantage of the well-known binding affinity of avidin to biotin, biotinylated antibodies can bind their specific antigen and be visualized by adding peroxidase to catalyze a colour producing reaction. Given that renal tissue contains abundant endogenous biotin, ${ }^{8}$ it may be erroneously interpreted as a positive antigen antibody interaction. To avoid such pitfalls, several protocols to block endogenous biotin have been proposed. ${ }^{7,9}$ Such blocking protocols were used in our study and the resultant loss of IHC staining confirmed that the previous detected staining was indeed a reflection of the abundant endogenous biotin.

The first report investigating biotin content of tumours was published back in 1941 by researchers from Columbia University. ${ }^{2}$ Biotin was measured using a microbiological method that assessed biotin requirements of specific gramnegative soil bacteria. In this original report, a significantly decreased biotin content was observed in 2 human lung cancers and 2 colorectal cancers when compared to their adjacent non-neoplastic tissues. Similar to our study, this discrepancy 
Fahmy et al.

\begin{tabular}{|c|c|c|c|c|c|c|c|}
\hline Tumour type & & pT & $\mathbf{p N}$ & pM & $\begin{array}{c}\text { Fuhrman } \\
\text { grade }\end{array}$ & $\mathbf{n}$ & Total \\
\hline \multirow{28}{*}{ Renal tumours } & \multirow{8}{*}{ Upper tract UC } & \multirow[t]{3}{*}{ T1 } & No & Mo & I & 3 & \\
\hline & & & No & Mo & II & 1 & \\
\hline & & & NO & Mo & IV & 1 & \\
\hline & & $\mathrm{T} 2$ & No & Mo & IV & 1 & \\
\hline & & \multirow[t]{2}{*}{ T3 } & No & Mo & II & 1 & \\
\hline & & & N2 & M1 & III & 1 & \\
\hline & & \multirow[t]{2}{*}{ Tx } & $\mathrm{Nx}$ & $\mathrm{Mx}$ & III & 1 & \multirow[b]{2}{*}{10} \\
\hline & & & $\mathrm{Nx}$ & $\mathrm{Mx}$ & IV & 1 & \\
\hline & \multirow{5}{*}{ Chromophobe RCC } & \multirow[t]{2}{*}{ T1 } & No & M0 & 1 & 1 & \multirow[b]{5}{*}{5} \\
\hline & & & No & Mo & IV & 1 & \\
\hline & & $\mathrm{T} 2$ & No & MO & II & 1 & \\
\hline & & & No & Mo & III & 1 & \\
\hline & & T3 & No & MO & IV sarcomatoid & 1 & \\
\hline & \multirow{10}{*}{ Conventional RCC } & \multirow[t]{3}{*}{ T1 } & No & M0 & II & 10 & \multirow[b]{10}{*}{31} \\
\hline & & & No & Mo & III & 8 & \\
\hline & & & No & Mo & IV & 1 & \\
\hline & & \multirow[t]{2}{*}{$\mathrm{T} 2$} & No & Mo & II & 1 & \\
\hline & & & No & Mo & III & 3 & \\
\hline & & \multirow[t]{4}{*}{ T3 } & No & MO & II & 3 & \\
\hline & & & No & Mo & III & 2 & \\
\hline & & & N1 & M1 & III & 1 & \\
\hline & & & No & Mo & IV & 1 & \\
\hline & & $\mathrm{Tx}$ & $\mathrm{Nx}$ & $\mathrm{Mx}$ & III & 1 & \\
\hline & \multirow{3}{*}{ Papillary type I RCC } & T1 & No & Mo & II & 2 & \\
\hline & & $\mathrm{T} 2$ & No & Mo & II & 1 & \\
\hline & & T3 & N2 & M1 & IV & 1 & \\
\hline & Papillary type II RCC & $\mathrm{T} 2$ & No & M0 & III & 1 & 5 \\
\hline & Oncocytoma & T1 & No & M0 & & 1 & 1 \\
\hline \multirow{3}{*}{$\begin{array}{l}\text { Testicular } \\
\text { tumours }\end{array}$} & Seminoma & T1 & No & M0 & & 1 & \\
\hline & \multirow{2}{*}{$\begin{array}{l}\text { Non seminoma } \\
\text { mixed germ cell }\end{array}$} & T1 & No & Mo & & 2 & \\
\hline & & $\mathrm{T} 2$ & No & Mo & & 1 & 4 \\
\hline
\end{tabular}

was not due to tumour necrosis. A Canadian study in 1949 tested biotin content in 22 malignant tumours and 9 normal tissues. ${ }^{10}$ Similarly, biotin was measured using a microbiological method utilizing yeast. While there was no biotin detected in pancreatic tumours, its levels were lower in kidney and liver tumours compared to their normal tissue counterparts. Conversely, gastrointestinal tumours were found to have more biotin content than the normal corresponding tissue.

In 1997, Italian researchers used IHC to investigate the restoration of endogenous biotin reactivity in formalin fixed tissues using antigen retrieval protocols. ${ }^{11}$ Retrieved endogenous biotin expression in archived tumours was compared to its expression in normal tissues obtained from other patients. An intense diffuse endogenous biotin reactivity was retrieved in 3/5 RCC, $1 / 1$ oncocytoma and 1/1 testicular leydig cell tumour. Conversely, 2/2 chromophobe RCC, 3/3 seminomas, 4/4 embryonal carcinomas, 5/5 hepatocellu- lar carcinoma, 20/20 lung and 20/20 breast cancers did not show any endogenous biotin reactivity. In this Italian study, all tested normal renal and testicular tissues had strong endogenous biotin staining. Likewise in 2008 and 2009, a group of investigators from the University of Wisconsin published 2 articles investigating retrieved endogenous biotin expression in a tissue microarray construct of renal tumours. ${ }^{12,13}$ While only $7 \%$ of chromophobe RCC expressed endogenous biotin, $77 \%$ of normal renal tissue and $93 \%$ of oncocytomas expressed strong staining. The conventional and papillary RCC had no endogenous biotin expression. Authors additionally reported endogenous biotin expression in about one-third of a subset of conventional and papillary RCC that exhibited granular/esinophilic (G/E) morphological features. These results, however, are not supported by our study. We did not study sufficient numbers of oncocytomas to make any conclusions. Further evaluation is required. 
Biotin in renal and testicular tumours

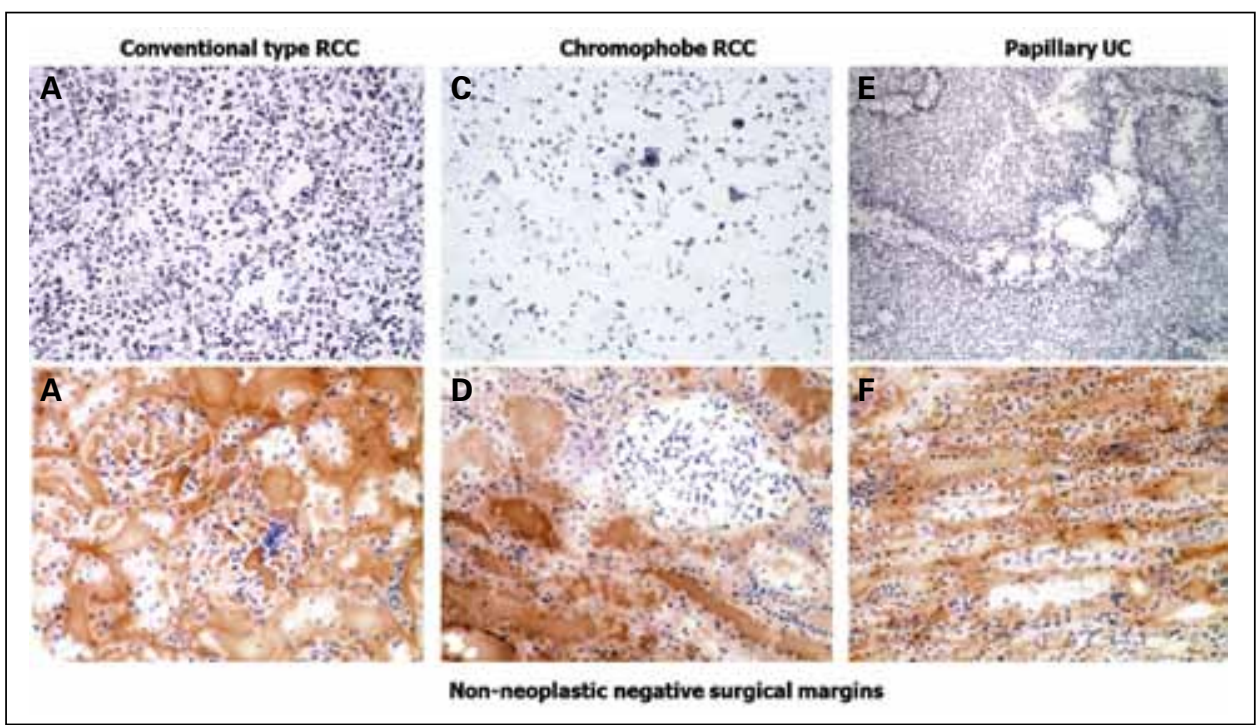

Fig. 1. Immunohistochemistry staining for endogenous biotin within selected tumours $(A, C, E)$ and their respective non-neoplastic negative surgical margins. A: Renal cell carcinoma (RCC), conventional type, GIII, $200 \times$ magnification; B: Non-neoplastic surgical margin tissue adjacent to A, $200 \times$ magnification; C: RCC, chromophobe, $200 \times$ magnification; D: Non-neoplastic surgical margin tissue adjacent to C, $200 \times$ magnification; E: transitional cell carcinoma, papillary type, Low grade, $100 \times$ magnification to show the papillary architecture; F: Non-neoplastic surgical margin tissue adjacent to $E, 200 \times$ magnification.

This is the first study to investigate biotin localization and expression in fresh frozen renal and testicular tumours while comparing this expression to their corresponding non neoplastic negative surgical margin surrounding the same tumour. This is also the first study, to our knowledge, to test endogenous biotin in upper tract UC. In this study there was no biotin expressed in all tested tumour samples, while strong endogenous biotin was expressed in the surrounding non-neoplastic margin of all renal tissues. A potential explanation for the absence of biotin content in malignant tumours may be at least in part due to their increased metabolism resulting in significantly higher biotin demands and, as such, biotin staining will not be detectable via IHC. Indeed, lower levels of biotin were found in the heart, liver and kidneys of rat embryos during their rapid growth when compared to their adult equivalents.

This study has several limitations. This is a retrospective pilot study with limited number of samples. Furthermore, non-neoplastic surgical margins rather than normal kidney tissues served as controls and no additional metabolic tumour profiling was performed using commercially available cell lines and tissue cultures. The number of tumours sampled was limited, especially for specific subtypes. Lastly, this study is a single group observation and further external validation is needed prior to generalization of these results across tumour subtypes and institutions.

The absence of biotin may potentially be used by pathologists as an affordable tumour marker. Biotin detection may also be exploited in the future in real-time using existing protein profiling technologies. ${ }^{14}$

\section{Conclusion}

We found that no biotin signal was perceived in all tested tumour samples. Endogenous biotin expression was detected in the matching non-neoplastic surgical margin of tested renal tissues. This lack of staining may prove to be a valuable tool in future studies. Moreover, when additional prospective studies further characterize the biotin relationship in RCC, the biotin pathway may possibly be used for targeted therapy.

Acknowledgement: This work was funded by a Young Investigator Grant from the Northeastern Section of the American Urological Association to Dr. Pautler.

Competing interests: Dr. Fahmy, Mr. Woo, Dr. Alameldin, Dr. King Lee, Dr. MacDonald, Dr. Goneau, Dr. Cadieux and Dr. Burton declare no competing financial or personal interests. Dr. Pautler has received unrestricted grants-in-aid from Paladin and Sanofi. He is also participating in an ongoing clinical trial with Astellas.

This paper has been peer-reviewed.

\section{References}

1. Canadian Cancer Society's Steering Committee on Cancer Statistics. Canadian Cancer Statistics 2012. Toronto, ON: Canadian Cancer Society; 2012. http://goo.gl/sg60MD. Accessed July 29, 2014.

2. West PM, Woglom WH. The biotin content of tumors and other tissues. Science 1941;93:525-7. http:// dx.doi.org/10.1126/science.93.2422.525-a 
Fahmy et al.

3. Roth KS. Biotin in clinical medicine-a review. Am J Clin Nutr 1981;34:1967-74.

4. Subramanya SB, Subramanian VS, Kumar JS, et al. Inhibition of intestinal biotin absorption by chronic alcohol feeding: Cellular and molecular mechanisms. Am J Physiol Gastrointest Liver Physiol 201 1;300:G494501. http://dx.doi.org/10.1152/aipgi.00465.2010

5. Krause KH, Bonjour JP, Berlit P, et al. Biotin status of epileptics. Ann N Y Acad Sci 1985;447:297-313. http://dx.doi.org/10.1111/i.1749-6632.1985.tb18447.x

6. Du Vigneaud V, Spangler JM, Burk D, et al. The procarcinogenic effect of biotin in butter yellow tumor formation. Science 1942;95:174-6. http://dx.doi.org/10.1126/science.95.2459.174

7. Wood GS, Warnke R. Suppression of endogenous avidin-binding activity in tissues and its relevance to biotin-avidin detection systems. J Histochem Cytochem 1981;29:1196-204. http://dx.doi. org/10.1177/29.10.7028859

8. Arvy L. The kidney and biotin [in French]. Laval Med 1969:40:1080-4.

9. Miller RT, Kubier P, Reynolds B, et al. Blocking of endogenous avidin-binding activity in immunohistochemistry: The use of skim milk as an economical and effective substitute for commercial biotin solutions. Appl Immunohistochem Mol Morphol 1999;7:63-5. http://dx.doi.org/10.1097/00022744-19990300000013

10. Ballantyne RM, Mc HE. Vitamin B6 and biotin in human cancer tissue. Cancer Res 1949:9:689-91
11. Bussolati G, Gugliotta P, Volante M, et al. Retrieved endogenous biotin: A novel marker and a potential pitfall in diagnostic immunohistochemistry. Histopathology 1997;31:400-7. http://dx.doi.org/10.1046/ i.1365-2559.1997.3020895.x

12. Huang $W$, Kanehira $K$, Drew $S$, et al. Oncocytoma can be differentiated from its renal cell carcinoma mimics by a panel of markers: An automated tissue microarray study. Appl Immunohistochem Mol Morphol 2009;17:12-7. http://dx.doi.org/10.1097/PAl.0b013e318173e79d

13. Kanehira K, Hu J, Pier T, et al. High endogenous avidin binding activity: An inexpensive and readily available marker for the differential diagnosis of kidney neoplasms. Int I Clin Exp Pathol 2008;1:435-9.

14. Cadieux PA, Beiko DT, Watterson JD, et al. Surface-enhanced laser desorption/ionization-time of flight-mass spectrometry (SELDI-TOF-MS): A new proteomic urinary test for patients with urolithiasis. J Clin Lab Anal 2004;18:170-5. http://dx.doi.org/10.1002/ida.20018

Correspondence: Dr. Stephen E. Pautler, Urology, St. Joseph Hospital, 268 Grosvenor St., London, ON N6A 4V2; fax: 519-646-6037; stephen.pautler@sihc.london.on.ca 